diminishing the need of frequent absences from the nest.

The positive evidence adduced by Cunningham and Reid in support of the 'emissive' function is merely that in certain cases the amount of oxygen in water of low oxygen content is increased when a Lepidosiren with pelvic flaments is placed in it. That this is so is only to be expected, seeing that the fish had access to the air and were allowed to breathe at intervals throughout the experiments. It would be more remarkable if the oxygen content of the water did not rise, for Mr. Cunningham himself has shown that in de-oxygenated water goldfish, perch and axolotls all allowed measurable quantities of oxygen to leak away. That oxygen is not given off by female Lepidosirens or by immature males is no doubt due to the epidermis not being thin enough to allow such diffusion to take place-even the gills are too thick (Fullarton ${ }^{11}$ ) - while on the other hand the breeding male, in the pelvic filaments, possesses an organ through which such diffusion can take place. If a male Lepidosiren, with filaments, is submerged in de-oxygenated water but is allowed to keep up the oxygen tension in its blood by breathing air into its lungs, a rise in the oxygen content of the water is only what is to be expected.
Before reliable conclusions can be reached, informa. tion must be sought as to what happens when males with filaments are denied access to atmospheric oxygen. Prof. Graham Kerr found that Lepidosirens, if prevented from breathing air, quickly die; an instructive and perhaps conclusive experiment could be performed if the times taken by ordinary male Lepidosirens to drown were compared with those taken by males with filaments. If the 'emissive' hypothesis is correct then the breeding males must die more quickly than the others.

Finally, it should be borne in mind that in all cases where oxygen is actually excreted from the blood, as in the air-bladders of certain fish, glands for that purpose are present; in the Lepidosiren no such structural modifications have been described.

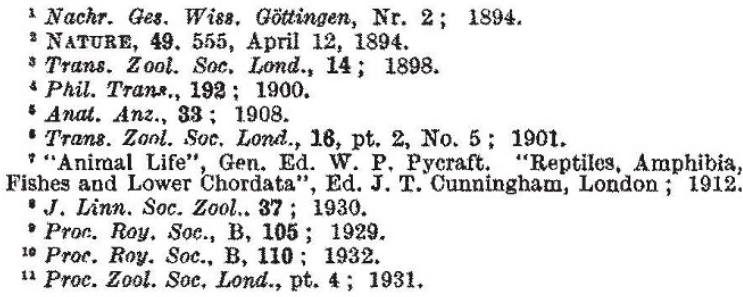

12 Proc. Zool. Sac, Lond., pt. 4; 1931.

\title{
Metals and Man*
}

$T$ HE first annual Research and Development lecture arranged by the British Science Guild was delivered, on May 16, in the hall of the Carpenters' Company, London, by Sir Harold Carpenter, his subject being "Metals in the Service of Human Life and Industry". Lord Melchett, who presided, said that the lecture had been instituted to direct attention to the importance of research - both purely scientific and technical-and the utilisation of its results for the benefit of mankind. The British Science Guild desired the lecture to be associated with the name of Sir Richard Gregory, who as Editor of NATURE, and in other activities, had done so much to secure increased recognition of the services rendered by science and scientific workers to progressive life.

Sir Harold Carpenter began his lecture by pointing out that, of the products of the physical universe which have contributed most to the comfort of the human race and the industrial progress of the world, metals are entitled to the first place. Man's most striking achievements have depended largely on the use of metals, as indicated by ships, bridges, railways, automobiles, power stations, aeroplanes, telegraph and telephone systems and broadcasting.

Leaving agriculture and fishing out of consideration, the beginning of metallurgy was the beginning of industry and also the beginning of civilisation. The material achievements of metallurgy constitute only a portion of its service to mankind, as it was in the practice of this art that man developed mental attributes which led to the foundation of science and modern thought. From the practice of this art men acquired the mental habit of inquiring into the phenomena observed in order to attain control over them and thus over Nature also. Chemistry developed from the old art of metallurgy,

" "Metals in the Service of Human Life and Industry". Pp. 39. British Science Guild, 6, John Street, Adelphi, W.C.2. 1s., including postage, 18. 1id. but engineering did not do so; yet in recent years the engineering, chemical, and metallurgical industries have reacted on each other in innumerable ways.

The core of the earth probably consists mainly of an alloy of iron and nickel, but the crust is of an entirely different composition. This crust has resulted from the gradual solidification of the earth from the state of a molten ball. During this solidifi. cation a sorting out of constituents has taken place, resulting in a layer of silicates on the surface containing originally very little metal, but during further cooling a differentiation of the constituents has taken place resulting in the separation of silicates and sulphides and the concentration of metals in certain parts.

The calculated composition of the accessible crust indicates that, of the metals, only aluminium and iron are present in appreciable amounts, and that all other metals taken together amount to less than half of one per cent. If these metals were uniformly distributed, metallurgy would not exist. The concentration of the metals in workable deposits in relation to concentration in the earth's crust varies from 4 to 5 times in the case of aluminium, to 4,000 to 15,000 times in the case of silver.

From the point of view of the rise and development of the metal arts from the earliest times, the industrial history of mankind may be divided into two major epochs-a stone age and a metal age. Between these there was a transitional period in which the metals, as found in their native state, were used as stones. The definite establishment of a metal age was due mainly to the discovery of the possibility of smelting metals from stones, and the importance of this discovery comes in the same category as the first method of producing fire artificially.

The metals gold and copper were the first to be used by man, and both were obtained from native metals. From the mere melting of a native metal 
to the smelting of an ore was a great advance, and this discovery was, in all probability, the result of an accident at the edge of a camp fire. The observation by the early workers that copper, as obtained from different deposits, had different properties, led to the mixing of other materials with the copper ore being smelted and ultimately to the production of bronze. It is generally recognised that so early as 3000 B.C., the Egyptians were skilled in the smelting and casting of copper, but the earliest authentic bronzes date from about 1600 B.C.

The next important discovery was the production of iron, and it is generally agreed that iron did not come into general use in Egypt until 1300 B.c., which may be taken as the beginning of the iron age. It appears that the Egyptians were acquainted with the carburising process for converting iron into steel about 1200 B.c., and with the quenching process for hardening steel about 900 B.C. After this, no important metallurgical discovery appears to have been made for a long time. Brass was first made at the beginning of the Christian era, and the next discovery of prime importance was that of cast iron, which was first made in the fourteenth century. This discovery was the outeome of the gradually increasing size of the furnaces used for making direct iron. The smelting of iron ores in large furnaces with the use of coke began early in the eighteenth century and marks the beginning of the modern iron and steel industry.

The next discovery of importance was the making of crucible steel at the end of the eighteenth century, but steel did not become available in large quantities until the invention of the Bessemer process in 1856.
During the last seventy-five years the development has been rapid and during the past thirty years more metal has been used than in all previous time.

Sir Harold Carpenter traced the progress of casting metal from the first castings in stone moulds to the modern methods of centrifugal and pressure die castings. The properties of metals, including strength, ductility and malleability received attention, and the chemical properties, especially as regards their resistance to the chemical action of their environment during service, that is, corrosion, were shown to be of the highest importance.

The effects of science on metallurgy have been most marked and important. So recently as just over a century ago, changes in metallurgical practice were mainly the result of chance discoveries or the consequence of a reaction to changing economic conditions. Scientific attention began to be directed to the systematic search for new alloys, new methods of mechanical and heat treatment, more economical methods of manufacture, better plant and greater reliability of product. The most conspicuous illustration of the influence of science on metallurgy is found in the case of aluminium. It is the most plentifully occurring metal in the earth's crust and yet has become available only within living memory. To-day, iron and aluminium are the two most important metals, iron having been used by man for over three thousand years and aluminium for under fifty years. The application of the methods of science to the ancient art of metallurgy, and the increased know. ledge gained thereby, will contribute ever increasingly to the amenities of human life and the progress of art and industry.

\section{Spectra of the Planets}

T HE annual George Darwin lecture was delivered at the Royal Astronomical Society's meeting on May 12; the lecturer being Prof. V. M. Slipher, director of the Lowell Observatory. He chose as his subject the spectra of the planets, the study of which has been, from the first, an important feature in the work of the Lowell Observatory. He noted that the advent of the spectroscope made it possible to learn something about the chemical composition of other worlds, and gave a sketch of the early work carried out by Sir William Huggins, using visual methods.

The introduction of photographic methods made a great advance possible; when the method was first used, the plates employed were insensitive to red light, and the infra-red region was quite excluded. Of late, the makers of plates have triumphed over these difficulties, and a great extent of the infra-red spectrum can now be photographed. This is specially important in planetary work, as there are many interesting lines and bands in this region.

An initial difficulty is that of separating planetary lines from those due to the terrestrial atmosphere. Prof. Slipher described different methods of discrimination; comparing a planet with the moon at the same altitude, or comparing the planet's spectrum at high and low altitudes. Also the terrestrial lines can be weakened by going to a high station. Some photographs have been taken at the San Francisco Peak, $11,000 \mathrm{ft}$. high, which is near the Observatory.
Another method, needing considerable dispersion, makes use of the shift of the planetary lines due to radial motion. This has been applied to Venus, with the result that oxygen cannot bo traced in its spectrum, but carbon dioxide is suspected. Great endeavours were made to test the rotation of Venus by the spectroseope. The slit was placed in various position angles, also with the spectroscope in two opposite positions, $180^{\circ}$ apart; the plates were shuffled, and the measurer kept in ignorance of the conditions of exposure, to prevent any possible bias. Unfortunately, no positive result was reached, but Prof. Slipher considers that ten days might be named as a lower limit to the planet's period of rotation.

Some twenty-five years ago there was a controversy as to the presence of the $a$ band, due to water vapour, in the spectrum of Mars. Lowell's book on the planet, published in 1909, included a reproduction of spectra taken by Prof. Slipher in 1908, showing the $a$ band stronger in the Martian spectrum than in the lunar one. Some doubt was thrown on this by other observers, but the presence of a small amount of water vapour is now generally accepted.

Prof. Slipher then proceeded to discuss the four giant planets; their spectra resemble each other in showing series of conspicuous bands, which increase in strength as we go from Jupiter to Neptune. Spectrograms of Jupiter were shown, which exhibited bands far in the infra-red, to wave-length 10,000 , but 8,600 was 